\title{
Local neighbourhood and mental health: evidence from the UK
}

\section{Carol Propper ${ }^{1}$, Kelvyn Jones ${ }^{2}$, Anne Bolster ${ }^{3}$, Simon Burgess ${ }^{1}$, Ron Johnston ${ }^{2}$, and Rebecca Sarker ${ }^{3}$}

\author{
1. Department of Economics and CMPO University of Bristol, \\ CASE and CEPR \\ 2. Department of Geography, University of Bristol \\ 3. CMPO, University of Bristol
}

\section{March 2004}

\begin{abstract}
Using a very local definition of neighbourhood, and characterising that neighbourhood along five relatively orthogonal dimensions based on the socioeconomic characteristics of the population of the neighbourhood, this paper examines the association between neighbourhood and levels and changes in mental health. We find that the extent of association between neighbourhood and both levels and changes in mental health is limited. While there are some individuals whose mental health is statistically associated with their neighbourhood composition, the importance of these differences is not large. What appears to be important for levels of mental health are the characteristics of individuals and their households, not place. Changes in mental health are not even associated with the characteristics that predict levels of health.
\end{abstract}

JEL No. I1, I12

Key words: mental health, neighbourhood, multilevel modelling

Acknowledgements

This research was funded by the UK Economic and Social Research Council as part of its Methods Programme http://www.ccsr.ac.uk/methods/ (grant H333250042): we are grateful for that support. The neighbourhood data associated with the BHPS have been provided by the Institute for Economic and Social Research at the University of Essex: we are very grateful to Prof. Nick Buck for his help in this.

Address for correspondence

Carol Propper

Department of Economics and CMPO

University of Bristol

Bristol BS8 1TN

Carol.Propper@bristol.ac.uk 


\section{Introduction}

The interest in neighbourhoods and mental health has a long history. As early as 1939, Farris and Dunham examined the relationship between neighbourhood and patients admitted to hospital for psychiatric problems and concluded that there was a link between the disorganisation of the neighbourhood and mental disorders. Despite this early interest, evidence on the association between neighbourhood and mental health is somewhat limited, particularly compared to the much larger body of evidence of the effect of local area on other outcomes such as poverty, unemployment, out of wedlock childbearing (e.g. Dietz 2002).

The evidence from the USA and the UK on the impact of neighbourhood on mental health is rather mixed. The small number of US studies find some impact (Silver et al 2002), while UK studies in the main find relatively little effect (Weich et al 2002). Several methodological issues arise in the study of the link between neighbourhood and mental health. First, data collected by health providers may contain little information on household and individual characteristics. As the location of individuals is not random, omission of these characteristics makes identification of neighbourhood effects difficult. Second, the only available measure of neighbourhood may be relatively large; for example, one common US measure of neighbourhood is a census tract (e.g. Silver 2002), which contains around 5000 individuals. Third, some studies have not had measures of the attributes of neighbourhood (e.g. Weich et al 2002), so have only been able to account for the proportion of variance accounted for by the neighbourhood level, rather than being able to link specific neighbourhood characteristics with mental health. Fourth, it is important in studies of area effects that the micro individual outcome (conditioning on individual characteristics) and the macro neighbourhood characteristics are modelled simultaneously.

We address these problems here. We examine the impact of neighbourhood using a very small definition of neighbourhood and measure the attributes of these neighbourhoods on five dimensions that have been found to be associated with poor social outcomes and, in some cases, mental health. Our sample is the BHPS, a panel data set of around 9000 individuals, which contains detailed measures of the sample individuals' mental health, their demographic and socio-economics characteristics and of those of their household (Taylor 2003). We construct, for each individual in the sample, 'bespoke' neighbourhoods (Buck 2001, Johnston and Pattie 2004) that contain the nearest $n$ people to each respondent. In this paper, we primarily focus on the smallest 
neighbourhood possible - the nearest 500-800 people to each sample member. We measure the characteristics of these neighbourhoods, using characteristics from the 1991 UK Census. Using factor analysis we measure neighbourhood type on 5 dimensions - socio-economic disadvantage, population mobility, demographic structure, ethnicity and urban-ness - based on the characteristics of the population in the neighbourhood.

Our measure of neighbourhood size - around 500 persons - is considerably smaller than used in recent US and UK studies. 500 persons is of the order of a one tenth of the size of the Census tract measure used in recent US studies, and at least a fifth of the size of the ward definition used in recent UK studies. In addition, we measure more dimensions of neighbourhood characteristics than have been used in large-scale studies to examine the relationship between health and place in both the UK and the US to date. Using these measures, we investigate the relationship between neighbourhood and the levels and changes in mental health, controlling for individual and household characteristics that may be associated with neighbourhood type. We estimate models that allow for within household correlation of errors and for the clustering of individuals within neighbourhoods.

We find the effect of neighbourhood, after allowing for differences between individuals who live in those areas, to be very small. Variance at the neighbourhood level accounts for little of the between individual variation in either levels of, or change in, mental health. On average, the characteristics of the bespoke neighbourhood in which the individual lives are not generally significantly associated with mental health levels or changes. In contrast, we find both observed individual and household characteristics are important determinants of levels of mental health. In common with other studies of mental health in the UK and the US, we find socio-economic status, race, gender and housing tenure are significant and important determinants of the levels of mental health. But while differences in the individual and household characteristics are associated with differences in the levels of mental health, these observed characteristics are not generally systematically associated with mental health trajectories over a 5 year period.

There is evidence of individual heterogeneity. For certain groups, poor mental health is associated with the characteristics of the neighbourhood in which they live. Women, those who are not white, and those who are less educated experience poorer mental health in some types of neighbourhood. But while these differences are statistically significant, their importance is small compared to the total variance in mental health outcomes and trajectories. 
The organisation of this paper is as follows. Section 1 reviews the evidence based on household survey data with information on both neighbourhoods and individual characteristics on the link between neighbourhood and mental health evidence. Section 2 presents our data. Section 3 presents our statistical approach. Section 4 presents the results and the final section our conclusions.

\section{Existing evidence}

\subsection{The relationship between mental health and neighbourhood}

Evidence for geographical variation in mental health outcomes is limited. In Britain, studies have concluded that there is no evidence of regional level variation in rates of anxiety and depression, after controlling for the characteristics of individual respondents (Cox et al 1987; Lewis and Booth 1992; Duncan et al 1995; Dorling, D. and Gunnell, D. forthcoming). Regions are large areas, defined for administrative purposes. However, two more recent studies reported similar findings using a much smaller definition of area, the electoral ward (Weich et al 2003, McCulloch 2001). ${ }^{1}$ Weich et al found that less than 1 percent of the total variance in common mental disorders, as measured by the General Health Questionnaire (GHQ), occurred at ward level. The variance was further reduced and was not statistically significant after adjusting for the characteristics of individuals. In contrast the proportion of variance at household level was statistically significant and remained so after adjusting for individual and household level confounders.

McCulloch (2001) used the first 8 waves of the BHPS to examine the relationship between a wardlevel deprivation index and a categorical variable based on the 12 item GHQ variable. ${ }^{2}$ This index was made up of four components: the unemployment rate, the proportion of household with no access to a car, the proportion of households with one or more persons per room, the proportion of households not owning their home. The sample was treated as a cross-section. McCulloch found that, after adjusting for characteristics of individuals, the area deprivation index had no significant explanatory power for individual mental health. There were, however, some differences across groups in that there were cross-level interactions between individual characteristics and area deprivation. In particular, McCulloch found significant interactions with tenure and gender, such that area appeared to have a larger effect for women resident in social housing. However, the effect of residence in social housing on health was not compounded by residence in a deprived area.

\footnotetext{
${ }^{1}$ A ward contains approx 2500 addresses.
} 
The number of US studies that combine individual and community level data is also limited (Silver et al 2002). Silver et al (2000) examined the relationship between two neighbourhood structural characteristics - neighbourhood disadvantage and neighbourhood mobility - and also control for individual and household characteristics. After controlling for these, they found that neighbourhood disadvantage was associated with higher rates of major depression and substance abuse disorder, and that neighbourhood residential mobility was associated with higher rates of schizophrenia, major depression and substance abuse disorder. The impact of individual characteristics was largely unaffected by inclusion of residential characteristics. They tested for, but did not find, any evidence that the effects of individual characteristics on mental disorders varied significantly across neighbourhood characteristics.

To date, only one study has examined changes in mental health in the UK. Hauck and Rice (2003) examined the degree of volatility in the GHQ score over time using the first seven waves of the BHPS. They estimated a multilevel model with time (measurement occasion) as level 1 and individuals as level 2 and control for a number of individual and household characteristics. They did not examine neighbourhood factors. They found that non-white ethnic groups have greater mobility in mental health status than white ethnic groups. Higher educational attainment was found to be associated with higher mobility in mental health outcomes. They also found that the unemployed, the retired, and individuals in lower social class groups have higher intra-individual correlation of GHQ scores across time i.e. low mobility of mental health outcomes compared to those in higher social class groups.

In summary, on average the existing literature points to a relatively weak association of neighbourhood and mental health, but there is evidence that for particular groups or particular aspects of health, neighbourhood may have stronger association.

\section{The Data}

We use the first ten waves ${ }^{3}$ of the British Household Panel Survey (BHPS) covering 1991-2000. The first wave of the BHPS was designed as a nationally representative sample of the population of Great Britain living in private households in 1991, and had a sample size of over 5,500 households

\footnotetext{
${ }^{2}$ Equals 1 if score more than 3 on the 12 item GHQ.
} 
covering over 10,000 people. Continuing representativeness of the (non-immigrant) population has been maintained by using a following rule typical of household panel surveys: at the second and subsequent waves, all original wave 1 sample members (OSMs) are followed (even if they move house, or if the household splits up), and there are annual interviews with all adult members of all households containing either an OSM, or an individual born to an OSM whether or not they were members of the original sample. New panel members who subsequently stop living with an OSM are, however, not followed and interviewed again. Thus, for example, if a non-OSM married an OSM at wave 2, and the partnership subsequently dissolved, the OSM is followed, but the nonOSM is not.

The sample for the analysis of the levels of mental health is all individuals present at the first year (1991) of the BHPS. We analyse the 8184 individuals located in 4341 households who have nonmissing information for all the covariates we use in our analysis. All data pertain to 1991. For the sample of 5-year changes in mental health we use the first observation of 5-year changes that is non- missing for each individual in our dataset. This means that we have observations from waves 1 to 5 of the BHPS. The sample size for the 5-year change in mental health is 7047 individuals located in 4377 households.

\subsection{The Measure of mental health}

As the measure of mental health we use the self-administered 12-item version of the General Health Questionnaire (GHQ) developed by Goldberg (1988). The GHQ concerns itself with the basic core of symptoms that are common to nearly all psychiatric patients. Using three calibration groups: 'normals', 'mildly ill' and 'severely ill', test items were chosen so that they differentiate psychiatric patients as a class from non-cases as a class. Respondents are presented with a number of statements concerning concentration, loss of sleep due to worry, perception of role, capability of making decisions, whether constantly under strain, perception of difficulty in overcoming problems, enjoyment of day-to-day activities, ability to face difficulties, depression, loss of confidence, selfworth, and general happiness. They are asked to compare recent experience of these items to their usual state on a four-point scale of severity. The highest well-being level scores 0 , and the worst well-being level scores 3 (Likert scoring scale). The scores to all twelve questions are summed. Thus the measure used here ranges from 0 (least distressed) to 36 (most distressed). The questionnaire gives an assessment of an individual's position on an axis from normality to

\footnotetext{
${ }^{3}$ We use the first wave of the BHPS for mental health levels, and waves 1 to 10 for mental health 5 year changes.
} 
undoubted illness, and can be thought of as giving a probability estimate of that individual being a psychiatric case.

The GHQ is highly correlated with standardised clinical interviews (Goldberg and Williams, 1988; Bowling, 1991). Goldberg and Williams (1988, p. 50) lists the six validity studies of the GHQ-12 that had been conducted prior to publication. The sensitivity rate (proportion of cases correctly identified) ranged from $71 \%$ to $91 \%$, and similarly the specificity rate (proportion of normals correctly identified) took values between $71 \%$ and $91 \%$. The variance weighted mean of the sensitivity and specificity rate from all these studies of the GHQ-12 was computed and found to be respectively $89 \%$ and $80 \%$.

We examine both levels and changes in this measure. The levels are measured in 1991. The changes are non-rolling five year changes. The first year of the change is the first year for which we observe the individual in the sample. For OSM members with full information, this is 1991. For individuals with missing information, or who enter the sample later, the first year of the five-year change is defined as the first year for which there is an observation of a five-year change.

Table 1 shows the average level of mental disorder, as measured by the GHQ, in 1991 and the average 5-year change, for our samples.

\subsection{Measures of neighbourhood}

We create a set of 'bespoke neighbourhoods' for each individual at each point in time. The smallest of these is based on the characteristics of the people in the nearest few streets; larger ones are constructed to reach certain size thresholds. Each individual's home postcode (these cover smaller numbers of locations than their US zipcode counterpart) is matched to an enumeration district (ED). These are the smallest data units for which UK census data are made available - at the 1991 census they contained around 500 people. Adjacent districts are then identified according to the distance between their centroids, and enumeration districts are aggregated into the bespoke neighbourhood until the required population or distance threshold is reached. In this paper we use the smallest spatial scale defined by population that is possible to use given the constraint of data confidentiality. 
This is approximately the nearest 500 people to the respondent's home address ${ }^{4}$. We also define a larger neighbourhood - the nearest 2000 persons - which we use in some preliminary analyses.

Having defined the bespoke neighbourhood, we characterise it using Census 1991 data for these ED sets. Eighteen variables were extracted from Census data, describing the socio-economic and demographic character of the ED. We construct a composite index of area characteristics at each of the spatial scales using factor analysis extracting the scores via principal components analysis (see Johnston et al 2004). We identify five factors. The first is essentially a measure of socio-economic disadvantage: it is increasing in unemployment, proportion living in local authority rented accommodation, having no car, long-term sick, single parent families, and decreasing in the proportion owning their homes outright, and employed in professional or managerial occupations. The second is a measure of spatial mobility and residential turnover. It contains high loadings on, and is increasing in, the proportion migrant in the previous year and the proportion living in oneperson non-pensioner households. The third is a measure of the age structure of the neighbourhood and contains high loading on the proportion of the population aged between 0 and 15 years, and the proportion of one-person pensioner households. Positive scores indicate neighbourhoods with relatively large numbers of children under 15; negative scores indicate areas with relatively high percentages of one-person pensioner households. The fourth is a measure of the extent to which the population in the neighbourhood is non-white and contains high loadings on and is increasing in the proportion that is of Pakistani, Bangladeshi, Indian or Black ethnic origin. The final factor is a measure of urban-ness and contains high loadings on, and is decreasing in the percentage of the labour force working in agriculture. The factor loadings are given in Table A1

These factors describe type of neighbourhood an individual lives in. The factors encompass attributes of the neighbourhood found to be important in previous research on mental health. Silver et al 2002 use two measures - neighbourhood disadvantage and neighbourhood residential mobilityboth defined very similarly to ours, but do not examine the effect of the three other factors.

The neighbourhood Census characteristics are only available for 1991, so our characterisation of a neighbourhood is fixed in time. We track individuals as they move neighbourhood, but the characterisation of their location is as it was at the 1991 census. For the analyses we do here, any measurement error will be small, as levels of mental health are measured in 1991 and most of the

\footnotetext{
${ }^{4}$ For reasons of confidentiality, no bespoke neighbourhood covers only one enumeration district. This means that the
} 
five year changes are relative to a 1991 base year. In the analyses we define centiles of each factor. Each centile contains roughly 43 households.

\subsection{Individual and household characteristics}

To link to previous findings (Weich and Lewis 1998, Weich et al 2003), age, gender, ethnicity, and education were all included as individual level determinants of mental health. Household characteristics include a measure of net household income ${ }^{5}$, the number of adults, the number of children, a set of dummy variables measuring type of household tenure, and a set of dummy variables measuring the employment status of the head of household.

Table A2 presents the means of all the variables for the sample used in the analysis ${ }^{6}$. Table A3 presents the correlations between the individual and household characteristics and the neighbourhood variables.

\section{Statistical procedures}

We address the following questions. First, is neighbourhood correlated with the incidence of mental health and if so, which characteristics of neighbourhood matter most? Second, does the association of neighbourhood characteristics remain after controlling for individual and household characteristics? Third, is the association between neighbourhood and health different across individuals, defined by race, gender and socio-economic status?

These hypotheses are investigated for both levels and changes in mental health. GHQ scores were analysed as a continuous measure. We begin by graphically examining the distribution of mental health levels and 5-year changes across each of the measures of neighbourhood types. We then undertake statistical analyses. All analyses are undertaken using multilevel modelling ${ }^{7}$, to allow for the hierarchical nature of the data. Individuals are clustered within households and households are clustered within bespoke neighbourhoods. We start with a set of null, random effects models, for individuals nested within households within neighbourhoods. We estimate one model for each neighbourhood factor. This provides an estimate of the variance at individual, household and

\footnotetext{
number of persons in the neighbourhood definition we use here ranges from 500 to 900 .

${ }^{5}$ This is net annual household income, deflated to January 2001 prices and equivalised using the McClements scale, before housing costs (Bardasi, Jenkins, Rigg 2003).

${ }^{6}$ If individuals with very high mental health scores are in institutions they will not be in the sample.

${ }^{7}$ Using MLwiN software. Rasbash, J., Steele, F., and Browne, W. (2003) A User's guide to MLwiN, Centre for Multilevel modelling, Institute of Education, University of London
} 
neighbourhood level before individual and household characteristics are taken into account. In the second and third stages, individual and household characteristics are added to the model. At this stage we defined neighbourhood by both the nearest 500 people and the nearest 2000 . As there was no evidence that the results differed at the larger scale, all subsequent analyses were undertaken using the smaller definition of neighbourhood ${ }^{8}$.

Based on these analyses we then estimate 2 level models, in which individuals are nested within households and the characteristics of the neighbourhood are entered at the household level. We allow for non-linearity in the neighbourhood effects and test for interactions of neighbourhood effects with race, gender, and a measure of socio-economic status (having a degree).

The hierarchical models we estimate embody the assumption that individual and household level unobserved heterogeneity is orthogonal to the observed individual and household characteristics. To test this assumption we also estimated fixed effects models allowing for correlation between the household level error and the observed covariates (Greene 2003). The hypothesis of zero correlation between the observed and unobserved characteristics was not rejected, so only the multilevel results are reported below.

\section{Results}

We undertake analyses first, of the levels of mental health and second, of the 5-year changes.

\subsection{Levels of mental health}

The left-hand panels of Figure 1 show the distribution of mental health by quantiles (in this graphical analysis we use 20ths) of each of the five neighbourhood factors. Each panel presents the $10^{\text {th }}, 25^{\text {th }}, 50^{\text {th }}, 75^{\text {th }}$ and $90^{\text {th }}$ percentile of the distribution. If there were large neighbourhood effects we would expect to see some pattern in the distribution across the quantiles of the neighbourhood factor. Examination of the distribution of the median across the five neighbourhood types reveals little obvious differences in the distribution of mental health across neighbourhoods: the series remains constant at a score of around 10 . The $25^{\text {th }}$ and $10^{\text {th }}$ percentiles are similarly flat. There is greater volatility in the $75^{\text {th }}$ and particularly the $90^{\text {th }}$ percentile of the distribution. For the

\footnotetext{
${ }^{8}$ Variance at the neighbourhood level is smaller when we used the nearest 2000 people.
} 
disadvantage and ethnicity factors, the mental health at the $90^{\text {th }}$ percentile of the distribution worsens as the disadvantage and ethnic mix of the neighbourhood increase respectively.

The right hand panels show the variance of mental health across the quantiles of each factor. These panels indicate considerably volatility in the variance across the quantiles. For the disadvantage and ethnicity factors the variance in outcomes increases as the neighbourhood becomes more disadvantaged or ethnically mixed.

Table 2 shows the variance at individual, household and neighbourhood level for each of the 5 factors. Neighbourhood is defined as percentiles of each factor. The null model indicates that the estimated variance at neighbourhood level is small (in the order of $2 \%$ percent) and not significant for 4 of the 5 measures. Around 12 percent of the variance is at household level and accounts for a significant proportion of the variance in mental health. The variance estimate at the neighbourhood level is reduced when observed individual and household characteristics are added to the model (Model 2). The proportion of variance accounted for at the household level remains significant when observed individual and household characteristics are added to the model.

Given these results, all subsequent analysis were undertaken using 2 level models, with individuals nested within households, where the value of the neighbourhood factor was entered as a continuous variable at household level. We initially allowed each factor to have a linear effect at household level. We then extensively explored non-linearities in the impact of each factor, allowing for various specifications of higher order terms in each factor. As none of these higher order terms were significant, we focused our subsequent attention on only linear factors. We allowed for interactions between linear terms in each factor and fixed individual characteristics that explained a significant amount of variation at individual level. These were gender, race and education.

We first present the association between observed individual and household characteristics and mental health. Table 3 reports the coefficients on these characteristics. Poorer mental health is significantly associated with age, gender, race, education, household demographic structure, household tenure and socio-economic status. Mental health declines with age up to the mid-50s then improves. Women are in poorer mental health than men, non-whites are in poorer mental health than whites, education is monotonically associated with better health, those in single adults households have lower mental health, those in local authority rented housing have poorer mental health, and individuals who are unemployed, engaged in family care, or who are a student. 
Comparison across the size of the coefficient estimates indicates that the most important determinants of differences in levels of mental health are gender, race, housing tenure and occupation, with the largest impact coming from being out of the labour market (being unemployed, being a carer and being a student). This latter result is consistent with those found in Blanchflower and Oswald (2004) and Clark and Oswald (1994) who also find that being unemployed has the largest impact on mental health and wellbeing after controlling for similar individual and household characteristics.

Table 4 investigates the impact of the neighbourhood factors. In this table we report the coefficient on the neighbourhood factor and the chi-square statistic from the log-likelihood test of adding the extra neighbourhood variable (or variables in the cases where we allow for interaction terms). We base our analysis on this statistic to allow for the correlation between the neighbourhood factors and the individual level characteristics. Only when the neighbourhood factor adds significantly to explaining the variance in the outcome do we wish to attribute the effect to the neighbourhood level.

The first set of rows of Table 4 shows that four of the neighbourhood factors, entered linearly, do not explain a significant proportion of the variance in the model. However, the ethnic composition of the area appears to be significantly associated with mental health, such that individuals in areas that are less white have poorer mental health. While the overall fit of the model, as measured by the log-likelihood ratio test, is higher, adding the measure of the neighbourhood makes the coefficient on the race of the individual become smaller in magnitude and not significant at conventional levels ${ }^{9}$. We also allowed for all 5 factors to impact on mental health simultaneously. The results (not reported here) unsurprisingly confirm the analysis for each factor separately.

The next set of rows allows for non-linearities in the effect of each neighbourhood factor. The $\chi^{2}$ test shows that allowing for non-linearity does not improve the fit of the model. The next three sets of rows show the effect of allowing for interactions between gender, race and ethnicity with each neighbourhood factor as well as the level of the neighbourhood factor. The chi-square statistic tests these neighbourhood terms. The first of these sets indicates that being female interacts with the disadvantage of the area. Women experience higher levels of mental health than men in all neighbourhoods, and as the disadvantage of the neighbourhood increases, so does the gap between 
male and female levels of health. The next set of rows repeats this analysis for race. The chi-square tests indicate a significant interaction of race with the mobility of the population of the neighbourhood, and some indication that the disadvantage of the population of the neighbourhood interacts with race. The effect of these two interactions is such that being non-white protects individuals against the negative impact of greater disadvantage and greater mobility on mental health. Non-whites in the least disadvantaged and least mobile neighbourhoods have poorer mental health than whites. In contrast, non-whites in the poorer and more mobile neighbourhoods have around better mental health than whites. The penultimate set of rows repeats this analysis for higher education. The results indicate that individuals with better education are less likely to be mentally ill in areas with higher concentrations of non-white individuals. The final rows of the table test linear terms in each factor plus all three interaction terms. The results confirm those of the three rows above.

While these results indicate that interaction effects are statistically significant, the substantive impact of these effects is not established. To investigate these we calculate the difference in the predicted levels of mental health for a reference individual and then investigate the effect of allowing for both the levels and interaction terms in the neighbourhood factors. The reference group is male, skilled, white, a renter, with no qualifications, with all other individual and household characteristics evaluated at the mean. We evaluate differences in predicted mental health for the $10^{\text {th }}$ and $90^{\text {th }}$ percentile of the neighbourhood factor and for men compared to women, whites compared to non-whites, and those without qualifications compared to those with higher education.

Table 5 presents these predicted values. The rows give predicted values at the $10^{\text {th }}$ and $90^{\text {th }}$ percentile of each factor. The columns show the differences between predicted values for men and women, for whites and non-whites and for those without and those with higher education (with all other variable values set as indicated above). The highlighted numbers indicate the interaction estimates that are statistically significant. The results indicate that while the differences between groups may be statistically significant, the size of the effect is, in all cases, quite small. Women in the $10^{\text {th }}$ decile of area disadvantage have slightly higher mental health levels to men. In the $90^{\text {th }}$ decile of area disadvantage the difference is 1.35 points. This is around $1 / 3$ of a standard deviation of the mental health measure. Non-whites in the least poor and least mobile areas have poorer mental health than whites, the gap being 1.22 points for the $10^{\text {th }}$ decile of the disadvantage measure

\footnotetext{
${ }^{9}$ Undertaking the analysis for whites and non-whites separately indicates the impact of the ethnic mix of the
} 
and 1.32 points for the least mobile area. In contrast, non-whites in the poorest area have around a 0.04 point better mental health than whites and in the most mobile areas have around -0.35 points mental health than whites. Again, the biggest of these differences is only in the order of a $1 / 3$ of the standard deviation in mental health. Levels of mental illness amongst those with higher education and those without are similar in the least ethnically mixed neighbourhoods. In the most ethnically mixed neighbourhoods, those without higher education have an average level of mental health that is 0.65 points better than those with no education.

\subsection{Five year changes in mental health}

The left hand panels of Figure 2 show the distribution of five year changes in mental health by 20ths of each of the five neighbourhood factors. The neighbourhood factors are all measured at the start of the five-year window for each individual. The median level of mental health is pretty much constant across the centiles for all five factors. There is more volatility in the $10^{\text {th }}$ and $90^{\text {th }}$ percentiles of the distribution, but no clear pattern is evident for all five factors. The right hand panels show the variance in mental health across the 20ths of each factor. These indicate considerable volatility in the variance but, with the possible exception of increasing variance as the ethnic mix of the neighbourhood increases, once again no very clear pattern is evident.

Table 6 shows the variance at individual, household and neighbourhood level, for each of the 5 factors. The null model indicates that the estimated variance at neighbourhood level was small (in the order of 3 percent at most) and not significant for any of the 6 measures. In contrast, around 1013 percent of the variance is at household level, and this is statistically significant. The variance estimates for level 3 are little changed when individual characteristics are added to the model (not shown), but when both individual and household characteristics are added to the model (Model 2) they increase slightly. The estimated variance accounted for by the ethnicity factor becomes statistically significant.

Given these results, all subsequent analysis was undertaken using 2 level models, with individuals nested within households, where the value of the neighbourhood factor was entered as a continuous variable at household level. We adopted the same procedure as for our analysis of the levels of mental health. We initially allowed for each factor to have a linear effect at household level, then explored non-linearities and interactions in gender, race and education.

neighbourhood is similar for whites and non-whites. 
Table 7 shows the association between individual and household characteristics (all measured at the start of the 5 year window) with changes in mental health (note a positive change indicates a worsening in health). Few observed characteristics are significantly associated with changes in mental health. The only characteristics significantly associated with changes in health are gender, being unemployed ${ }^{10}$ at the start of the five year window and being in the 'other' ${ }^{11}$ occupation category. The coefficients on these variables indicate that trajectories in health worsen for women than men and improve for those with the other two characteristics.

Table 8 shows the impact of neighbourhood factors. The first row of this second panel shows that two of the neighbourhood factors, entered linearly, are significantly associated with changes in mental health. These are the mobility and urban-ness of the neighbourhood. The disadvantage factor is associated with change at the 10 percent level. The next set of rows allows for non-linearity in the neighbourhood factors. The table indicates little non-linearity, except perhaps in the mobility factor. However, as the quadratic term is not significant, all subsequent analyses were undertaken using only linear terms in the factors.

The next block of rows show the effect of allowing for interactions between gender, race and ethnicity with the neighbourhood factors in addition to the level of the neighbourhood factors. The first of these rows indicates that being female interacts with both the mobility and the urban-ness of the area. As the mobility of the neighbourhood increases, so does the gap between male and female levels of health. The next set of rows repeats this analysis for race. The chi-square tests indicate a significant interaction of race with the mobility of the area. The effect of this interaction is such that non-white individual in more mobile neighbourhoods experience significantly worse change in their mental health than whites. There is also a significant association between ethnicity of area and ethnicity of the individual. Non-whites in more ethnically mixed areas experience better mental health trajectories than whites. The next sets of rows repeat the analysis for education. The only interaction that is significant is that for neighbourhood disadvantage. Better-educated individuals have worse trajectories in mental health in less advantaged areas. The last set of rows allows for all interactions plus the linear term in each factor. Again, this confirms the analyses of the three sets of rows above.

\footnotetext{
${ }^{10}$ We cannot establish here whether this is due to leaving unemployment or to heterogeneity.
} 
To examine the importance of these interaction effects we made the same comparison of predicted values of trajectories of mental health as we undertook for the levels. The results are given in Table 9. They indicate that the effects of the interaction terms are again relatively small when compared to the standard deviation of the change in mental health. Predictions relating to significant interactions are highlighted. Women in the least mobile area have very similar changes in mental health to men: in the most mobile area the difference in the level is of the order of 0.76 points. This is around 1/6 of the standard deviation in the change in mental health. Women in the most urban areas experience similar changes in mental health to men: in contrast, those in the most rural areas experience a 0.70 point worse health change than men. Non-white individuals in the least mobile neighbourhoods have slightly better trajectories in mental health than whites. In contrast, in the most mobile neighbourhoods, non-whites experience nearly 1.47 points greater change in mental health than whites. This is the largest difference for the types of individuals examined here and is about one third of a standard deviation of the mental health change variable. Better-educated individuals have better trajectories in richer areas, but worse ones in poorer areas. The biggest gap between those with and without higher education is -0.88 points: again this is relatively small compared to the overall variance in the 5-year change in mental health.

\section{Discussion}

We have examined the association between neighbourhood and levels and changes in mental health using a very local definition of neighbourhood, and measures of five dimensions of this neighbourhood based on the residents in 1991. This study is one of only a handful that examines the association between individual, household characteristics and neighbourhood characteristics on mental health. In addition, it is the first study of the association between trajectories in mental health and neighbourhood in the UK.

Our results suggest the extent of association between neighbourhood and levels and changes in mental health is limited. The relationship between neighbourhood and levels and changes are not large, compared to the differences across individuals and households. There is a negative association between mental health and neighbourhoods that are more disadvantaged, have more mobile populations, and are more urban. There is some indication that the ethnicity of individuals in the neighbourhood is associated with levels of mental health. But this cannot be confidently

\footnotetext{
${ }^{11}$ Armed forces, long term sick or disabled, government training.
} 
interpreted as a 'neighbourhood effect' since individuals who are non-white both experience poorer mental health and are more likely to live in areas in which a smaller proportion of residents are white.

We also find that the experience of neighbourhood differs across individuals. These differences are particularly associated with race - either of the individual or of the neighbourhood - and with gender. Individuals who are not white (3\% of the sample) have poorer mental health in neighbourhoods containing more disadvantaged and more mobile people. Individuals who are less educated experience worse mental health in non-white neighbourhoods. The health of individuals who are not white improves more than other individuals in neighbourhoods that have a more mobile population. Women are more likely to experience lower levels of mental health in poor neighbourhood and their change in mental health is more likely to be worse than that of men when they live in neighbourhoods containing more mobile and more rural populations. However, whilst these differences are statistically significant, when we examine the estimated magnitude of the effects we find them to be small compared to the variability across individuals in levels and changes in mental health.

Individual and household characteristics are more important than neighbourhood characteristics in explaining variance across individuals. The percentage of total variance explained by observed characteristics is in the order of $10 \%$, which, while small, is not out of line with other studies of variation in mental health across individuals. Our results confirm many previous studies that show that levels of mental health are strongly associated with certain observed individual and household characteristics in the UK (e.g. Weich et al). However, our findings for changes in mental health indicate that few observed individual and household characteristics are associated with changes in mental health. Put another way, knowing who has poorer mental health will not provide much information about the trajectory of their mental health.

In sum, the characteristics of the very local neighbourhood of an individual in the UK - once we allow for the fact that individuals differ in their spatial location - is relatively unimportant in determining either levels or trajectories of common mental health disorders. What matters for mental health are the characteristics of individuals and their households. Interactions at a neighbourhood level do not appear to have an effect on mental health, after allowing for the nature of the individuals who live in the neighbourhood. 
We have not made any claims here about the causality or otherwise of the neighbourhood effect. Identification of neighbourhood effects is plagued by individual heterogeneity. We have allowed for considerable individual heterogeneity, and have shown that once we control for this, only a small amount of the variation in outcomes - in either the levels or changes in mental health - is associated with the neighbourhood. These results suggest that even if any of the association were causal - that neighbourhoods had an effect on the mental health of the individuals living in them - the impact of neighbourhood on mental health in the UK would be small, unless individuals who were prone to poorer mental health sorted into types of neighbourhood which affected mental health positively.

We have shown here that this does not appear to be the case. First, very little of the variance in outcomes is explained by the neighbourhood factors. Second, sorting of individuals in the UK does not seem to be such that individuals who experience poorer mental health live in neighbourhoods with high proportions of people who do not experience poor mental health. For example, we find individuals who are not white to have poorer mental health than those who are white. In addition, individuals who are not white are more likely, rather than less likely to live in neighbourhoods with a lower proportion of whites in them. Similarly, we find that lower household income is associated with poorer mental health, and that such individuals are more likely to live in small locales characterised by high proportions of similarly low-income individuals. We leave further investigation of this issue to future research.

Finally, the implication of these results, together with findings from recent UK research that used a larger scale definition of neighbourhood, is that is it people, rather than place, that matter. This suggests that people and their households should be the focus of policy effort to alleviate the common mental health disorders examined here. 


\section{References}

Bardasi, E., Jenkins, S.P., and Rigg, J. A. (2003) Documentation for derived current and annual net household income variables, BHPS Waves 1-10.

http://www.dataarchive.ac.uk/doc/3909\%5Cmrdoc\%5Cpdf\%5C3909userguide.pdf

Blanchflower, D., and Oswald, W. (2004) Well-Being Over Time in Britain and the USA. Journal of Public Economics, 88, 1359-1386.

Bowling, A. (1991) Measuring Health. A Review of Quality of Life Measurement Scales. OUP, Milton Keynes.

Buck, N. (2001) Identifying neighbourhood effects on social exclusion. Urban Studies, 38, 22512275.

Clark, A., and Oswald, W. (1994) Unhappiness and Unemployment. Economic Journal, 104, 648659.

Cox, B. D., Blaxter, M., Buckle, A. L. J., et al. (1987) The Health and Lifestyle Survey. First Edition Cambridge, United Kingdom: Health Promotion Research Trust 1987.

Dietz, R. D. (2002) The estimation of neighborhood effects in the social sciences: An interdisciplinary approach. Social Science Research, 31, 539-575.

Dorling, D. and Gunnell, D. (forthcoming). Suicide: the spatial and social components of despair in Britain 1980-2000. Transactions of the Institute of British Geographers 2004

Duncan, C., Jones, K., and Moon, G. (1995) Psychiatric morbidity: a multilevel approach to regional variations in the UK. Journal of Epidemiology and Community Health, 49, 290295.

Faris, R. E., and Dunham, H. W. (1939) Mental disorders in urban areas: An ecological study of schizophrenia and other psychoses. Chicago/London: The University of Chicago Press.

Goldberg, D., and Williams, P., (1988) A User's Guide to the General Health Questionnaire. NFER-NELSON. Windsor.

Greene, W. (2003) Econometric Analysis. Fifth edition. Prentice-Hall.

Johnston, R., Jones, K., Burgess S., Propper, C., Sarker, R., Bolster, A. (2004) Fractal Factors? Scale, Factor Analysis \& Neighbourhood Effects. Geographical Analysis, 36.

Johnston, R. J., and Pattie, C. J. (2004) Putting voters in their place: local context and voting in England and Wales, 1997. In A. S. Zuckerman, editor, The Social Logic of Politics: Family, Friends, Neighbors and Workmates as Contexts for Political Behavior. Cambridge: Cambridge University Press. 
Lewis, G., and Booth, M. (1992) Regional differences in mental health in Great Britain. Journal of Epidemiology and Community Health, 46, 608-611.

McCulloch, A. (2001) Ward-level deprivation and individual social and economic outcomes in the British Household Panel Study. Environment and Planning A, 33, 667-84.

Rice, N., and Hauck, K. (2003) A longitudinal analysis of mental health mobility in Britain. Paper presented at Twelfth European Workshop on Econometrics and Health Economics 17th-20th September 2003.

Silver, E., Mulvey, E. P., and Swanson, J. W. (2002) Neighborhood Structural Characteristics and Mental Disorder: Faris and Dunham Revisited. Social Science and Medicine, 55, 1457-1470.

Taylor, M. F., (ed). with Brice, J., Buck, N., and Prentice-Lane, E. (2003) British Household Panel Survey User Manual Volume A: Introduction, Technical Report and Appendices. Colchester: University of Essex.

Weich, S., and Lewis, G. (1998) Material Standard of living, social class and the prevalence of common mental disorders in Great Britain. Journal of Epidemiology and Community Health, 52, 8-14.

Weich, S., Holt, G., Twigg, L., Jones, K., and Lewis, G. (2003) Geographic Variation in the Prevalence of Common Mental Disorders in Britain: A Multilevel Investigation. American Journal of Epidemiology, 157, 730-737. 
Table A1. Loadings on the five principal component factors of bespoke neighbourhood characteristics at the nearest 500 people scale

\begin{tabular}{lccccc}
\hline & Disadvantage & Mobility & Age & Ethnicity & Urban-ness \\
\% Unemployed & 0.823 & 0.344 & 0.06 & 0.422 & -0.061 \\
\% Long term sick aged 16-60/64 & 0.813 & -0.056 & -0.165 & 0.135 & -0.028 \\
\% Owned outright & -0.611 & -0.452 & -0.485 & -0.073 & -0.171 \\
\% Local authority & 0.862 & 0.039 & 0.127 & -0.023 & 0.157 \\
\% Central heating & -0.372 & -0.298 & 0.175 & -0.303 & 0.541 \\
\% Exclusive facilities & 0.015 & -0.385 & 0.104 & -0.149 & 0.631 \\
\% No Car, & 0.862 & 0.424 & -0.256 & 0.297 & 0.009 \\
\% Density > 1 person per room & 0.5 & 0.299 & 0.27 & 0.761 & -0.165 \\
\% Lone parent & 0.771 & 0.239 & 0.424 & 0.205 & 0.121 \\
\% One person pensioner & 0.261 & -0.025 & -0.818 & -0.089 & 0.011 \\
\% One person non-pensioner & 0.173 & 0.887 & -0.132 & 0.235 & -0.123 \\
\% Black & 0.229 & 0.425 & 0.174 & 0.544 & 0.143 \\
\% Indian & -0.008 & 0.07 & 0.072 & 0.768 & 0.09 \\
\% Pakistani \& Bangladeshi & 0.146 & 0.109 & 0.077 & 0.83 & -0.142 \\
\% Migrant in last year & -0.028 & 0.825 & -0.003 & 0.127 & -0.093 \\
\% Working in agriculture & -0.16 & -0.214 & 0.087 & -0.186 & -0.662 \\
\% children (aged 0-15 years) & 0.299 & -0.222 & 0.823 & 0.26 & 0.096 \\
\% prof-managerial & -0.703 & 0.125 & -0.011 & -0.142 & 0.048 \\
\hline
\end{tabular}

Extraction Method: Principal Component Analysis. Rotation Method: Oblimin with Kaiser Normalization. 
Table A2. Summary statistics of variables used.

\begin{tabular}{|c|c|c|c|c|}
\hline Variable Label & Mean & Std. Dev. & Min & Max \\
\hline Mental Health Level & 10.639 & 4.79 & 0 & 36 \\
\hline Mental Health 5 year change & 0.643 & 5.80 & -27 & 29 \\
\hline Disadvantage Factor p500f1 & -0.084 & 0.94 & -1.887 & 3.427 \\
\hline Mobility Factor p500f2 & -0.026 & 0.98 & -1.962 & 6.355 \\
\hline Age Factor p500f3 & 0.001 & 0.97 & -3.648 & 4.212 \\
\hline Ethnicity Factor p500f4 & 0.015 & 0.99 & -1.273 & 10.589 \\
\hline Urban-ness Factor p500f5 & 0.018 & 0.95 & -8.088 & 2.325 \\
\hline Age & 43.211 & 18.07 & 15 & 97 \\
\hline Age squared & 2193.741 & 1738.68 & 225 & 9409 \\
\hline Female & 0.515 & 0.50 & 0 & 1 \\
\hline Nonwhite & 0.033 & 0.18 & 0 & 1 \\
\hline No qualifications/Still at school & 0.281 & 0.450 & 0 & 1 \\
\hline Sub o-level & 0.094 & 0.29 & 0 & 1 \\
\hline O-level & 0.169 & 0.37 & 0 & 1 \\
\hline A-level & 0.297 & 0.46 & 0 & 1 \\
\hline Higher Education & 0.159 & 0.37 & 0 & 1 \\
\hline Household net income in $£ 000$ & 16.471 & 9.29 & 3.018 & 103.806 \\
\hline No. adults in household & 2.226 & 0.89 & 1 & 7 \\
\hline No. children in household & 0.599 & 0.96 & 0 & 6 \\
\hline Tenure: Owned outright & 0.211 & 0.41 & 0 & 1 \\
\hline Tenure: Owned with mortgage & 0.504 & 0.50 & 0 & 1 \\
\hline Tenure: Local authority rented & 0.164 & 0.37 & 0 & 1 \\
\hline Tenure: Housing association rented & 0.030 & 0.17 & 0 & 1 \\
\hline Tenure: Private rented & 0.091 & 0.29 & 0 & 1 \\
\hline Professional & 0.058 & 0.23 & 0 & 1 \\
\hline Manager & 0.211 & 0.41 & 0 & 1 \\
\hline Skilled Non-manual & 0.101 & 0.30 & 0 & 1 \\
\hline Skilled Manual & 0.203 & 0.40 & 0 & 1 \\
\hline Partly skilled/Unskilled & 0.105 & 0.31 & 0 & 1 \\
\hline Unemployed & 0.060 & 0.24 & 0 & 1 \\
\hline Retired & 0.195 & 0.40 & 0 & 1 \\
\hline Family care & 0.023 & 0.15 & 0 & 1 \\
\hline Student & 0.033 & 0.18 & 0 & 1 \\
\hline Other occupation & 0.010 & 0.10 & 0 & 1 \\
\hline
\end{tabular}

1. Sample size is 9334 . Of these, 8184 have a nonmissing data for the mental health level variable and 7047 nonmissing data for the mental health 5 year change variable. 


\begin{tabular}{|c|c|c|c|c|c|c|c|}
\hline & $\begin{array}{c}\text { Mental } \\
\text { Health } \\
\text { level in } \\
1991 \\
\text { (GHQ) }\end{array}$ & $\begin{array}{c}5 \text { year } \\
\text { change in } \\
\text { Mental } \\
\text { Health } \\
\text { (GHQ) }\end{array}$ & $\begin{array}{l}\text { Disadvant } \\
\text { age Factor } \\
\text { p500f1 }\end{array}$ & $\begin{array}{c}\text { Mobility } \\
\text { Factor } \\
\text { p500f2 }\end{array}$ & $\begin{array}{c}\text { Age } \\
\text { Factor } \\
\text { p500f3 }\end{array}$ & $\begin{array}{c}\text { Ethnicity } \\
\text { Factor } \\
\text { p500f4 }\end{array}$ & $\begin{array}{l}\text { Urban- } \\
\text { ness } \\
\text { Factor } \\
\text { p500f5 }\end{array}$ \\
\hline Mental Health level in 1991 (GHQ) & 1.00 & & & & & & \\
\hline $\begin{array}{l}5 \text { year change in Mental Health } \\
\text { (GHQ) }\end{array}$ & -0.49 & 1.00 & & & & & \\
\hline Disadvantage Factor p500f1 & 0.08 & 0.00 & 1.00 & & & & \\
\hline Mobility Factor p500f2 & 0.02 & 0.03 & 0.19 & 1.00 & & & \\
\hline Age Factor p500f3 & 0.01 & 0.00 & 0.05 & -0.02 & 1.00 & & \\
\hline Ethnicity Factor p500f4 & 0.03 & 0.00 & 0.19 & 0.24 & 0.06 & 1.00 & \\
\hline Urban-ness Factor p500f5 & 0.01 & -0.01 & -0.03 & -0.11 & 0.13 & -0.03 & 1.00 \\
\hline Age & 0.02 & -0.01 & 0.01 & -0.09 & -0.11 & -0.07 & -0.01 \\
\hline Age squared & 0.01 & -0.01 & 0.02 & -0.08 & -0.12 & -0.06 & -0.01 \\
\hline Female & 0.10 & 0.05 & 0.02 & 0.00 & -0.02 & -0.01 & 0.00 \\
\hline Nonwhite & 0.01 & 0.01 & 0.03 & 0.09 & 0.03 & 0.38 & 0.01 \\
\hline No qualifications/Still at school & 0.07 & 0.00 & 0.19 & -0.04 & -0.03 & 0.03 & 0.00 \\
\hline Sub o-level & 0.01 & -0.01 & 0.03 & -0.03 & 0.00 & 0.00 & 0.00 \\
\hline O-level & -0.01 & -0.01 & 0.00 & -0.06 & 0.00 & -0.04 & -0.01 \\
\hline A-level & -0.04 & 0.00 & -0.08 & 0.01 & 0.04 & 0.00 & -0.01 \\
\hline Higher Education & -0.03 & 0.01 & -0.14 & 0.12 & -0.02 & 0.01 & 0.02 \\
\hline Household net income in $£ 000$ & -0.08 & 0.02 & -0.26 & 0.03 & 0.03 & -0.02 & 0.06 \\
\hline No. adults in household & -0.07 & 0.01 & -0.06 & -0.12 & 0.04 & 0.04 & 0.02 \\
\hline No. children in household & 0.03 & 0.02 & -0.03 & -0.05 & 0.11 & -0.01 & 0.01 \\
\hline Tenure: Owned outright & -0.06 & 0.02 & -0.12 & -0.12 & -0.10 & -0.02 & -0.08 \\
\hline Tenure: Owned with mortgage & -0.02 & 0.01 & -0.20 & -0.06 & 0.07 & -0.03 & 0.06 \\
\hline Tenure: Local authority rented & 0.10 & -0.03 & 0.42 & 0.03 & 0.07 & -0.02 & 0.08 \\
\hline Tenure: Housing association rented & 0.01 & 0.01 & 0.11 & 0.12 & 0.04 & 0.11 & 0.02 \\
\hline Tenure: Private rented & -0.01 & -0.02 & -0.05 & 0.18 & -0.09 & 0.04 & -0.10 \\
\hline Professional & -0.01 & 0.00 & -0.11 & 0.01 & 0.01 & -0.02 & 0.05 \\
\hline Manager & -0.06 & 0.03 & -0.21 & 0.05 & -0.01 & -0.05 & 0.02 \\
\hline Skilled Non-manual & 0.01 & -0.01 & -0.03 & 0.00 & 0.00 & 0.01 & 0.02 \\
\hline Skilled Manual & -0.04 & 0.03 & 0.06 & -0.05 & 0.07 & 0.01 & 0.00 \\
\hline Partly skilled/Unskilled & 0.01 & -0.02 & 0.11 & 0.01 & 0.04 & 0.03 & -0.05 \\
\hline Unemployed & 0.11 & -0.04 & 0.10 & 0.04 & 0.02 & 0.06 & -0.02 \\
\hline Retired & -0.02 & 0.01 & 0.04 & -0.05 & -0.11 & -0.04 & -0.01 \\
\hline Family care & 0.02 & -0.01 & 0.00 & 0.09 & -0.03 & 0.08 & -0.01 \\
\hline Student & 0.11 & -0.02 & 0.15 & -0.03 & 0.00 & 0.01 & 0.01 \\
\hline Other occupation & 0.00 & -0.02 & 0.01 & 0.03 & 0.03 & -0.02 & -0.02 \\
\hline
\end{tabular}

Sample size is 9334 .

Full correlation matrix available from the authors upon request. 
Figure $1.10^{\text {th }}, 25^{\text {th }}, 50^{\text {th }}, 75^{\text {th }}, 90^{\text {th }}$ percentiles and Variance of Mental Health Level in 1991 (GHQ) by 20th of each factor: Wave 1 sample.
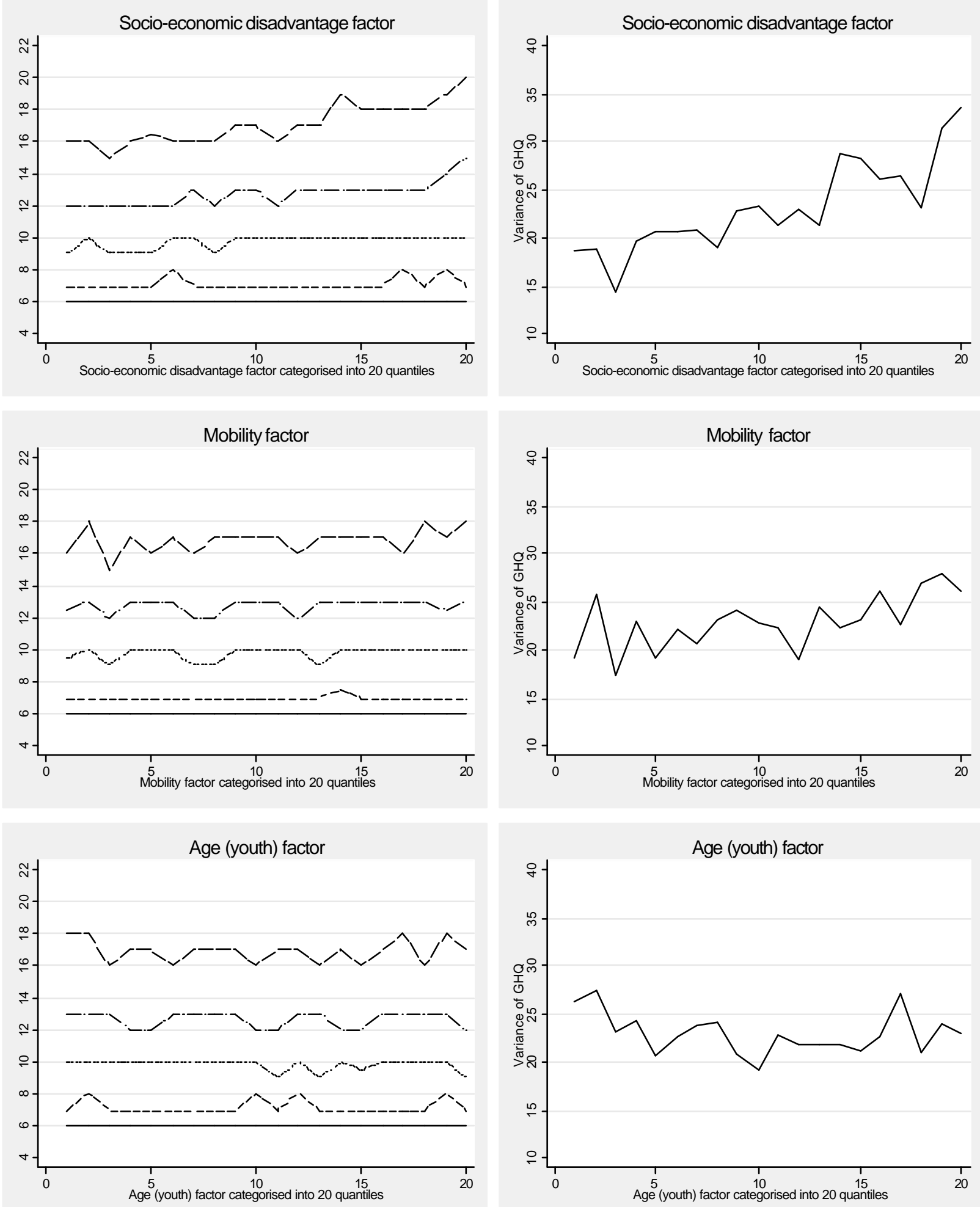

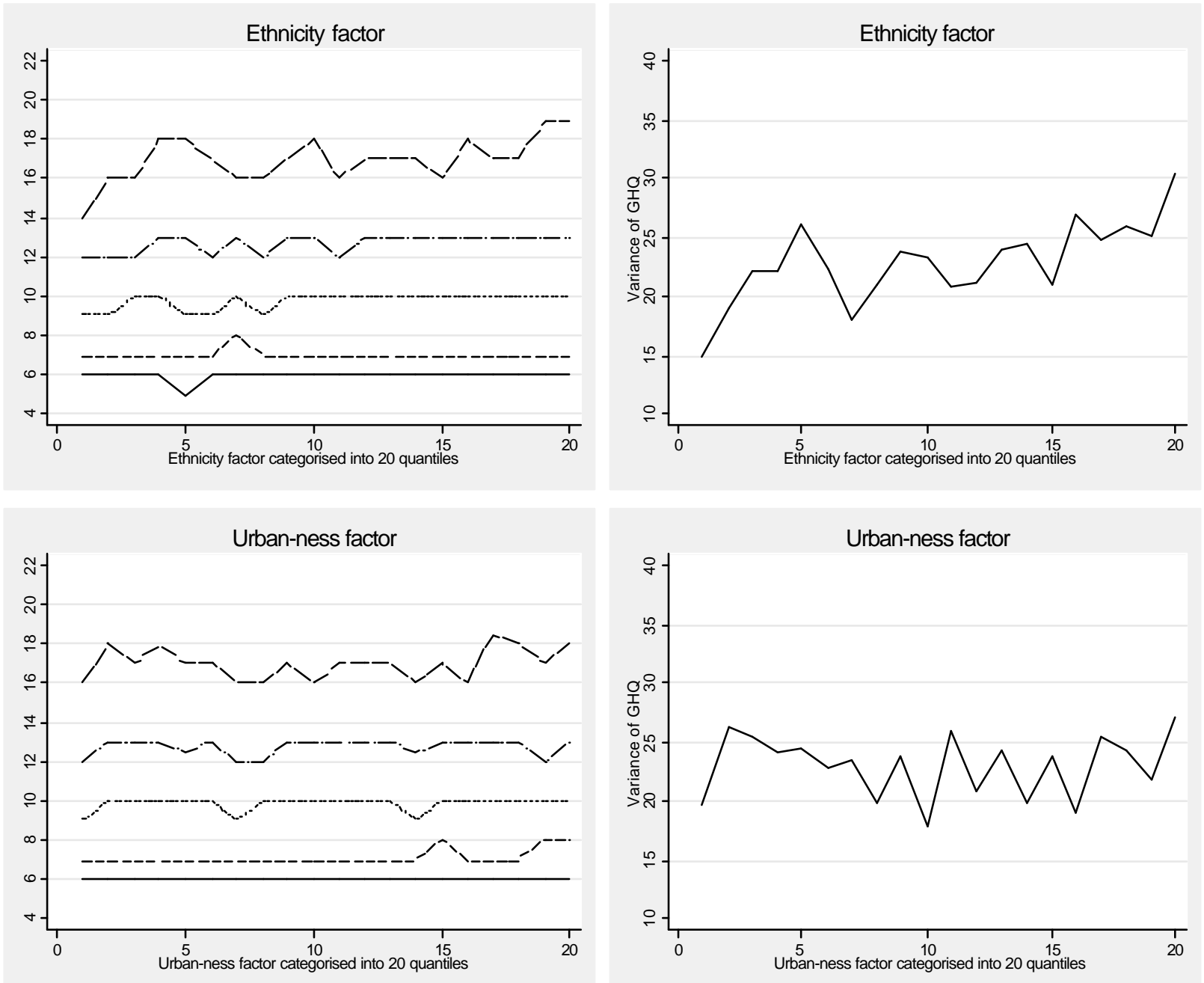
Figure $2.10^{\text {th }}, 25^{\text {th }}, 50^{\text {th }}, 75^{\text {th }}, 90^{\text {th }}$ percentiles and Variance of Mental Health 5 year change by 20th of each factor.
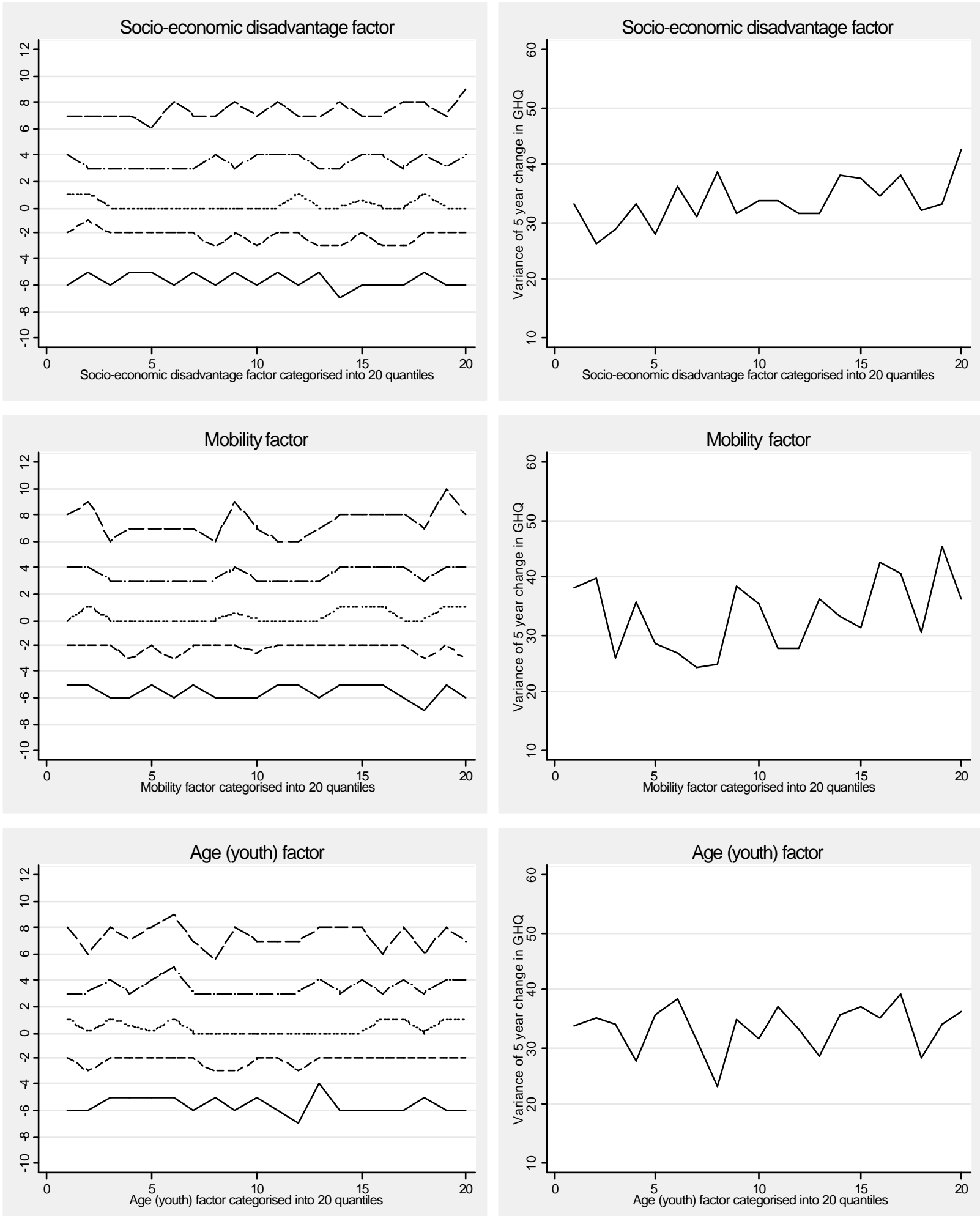

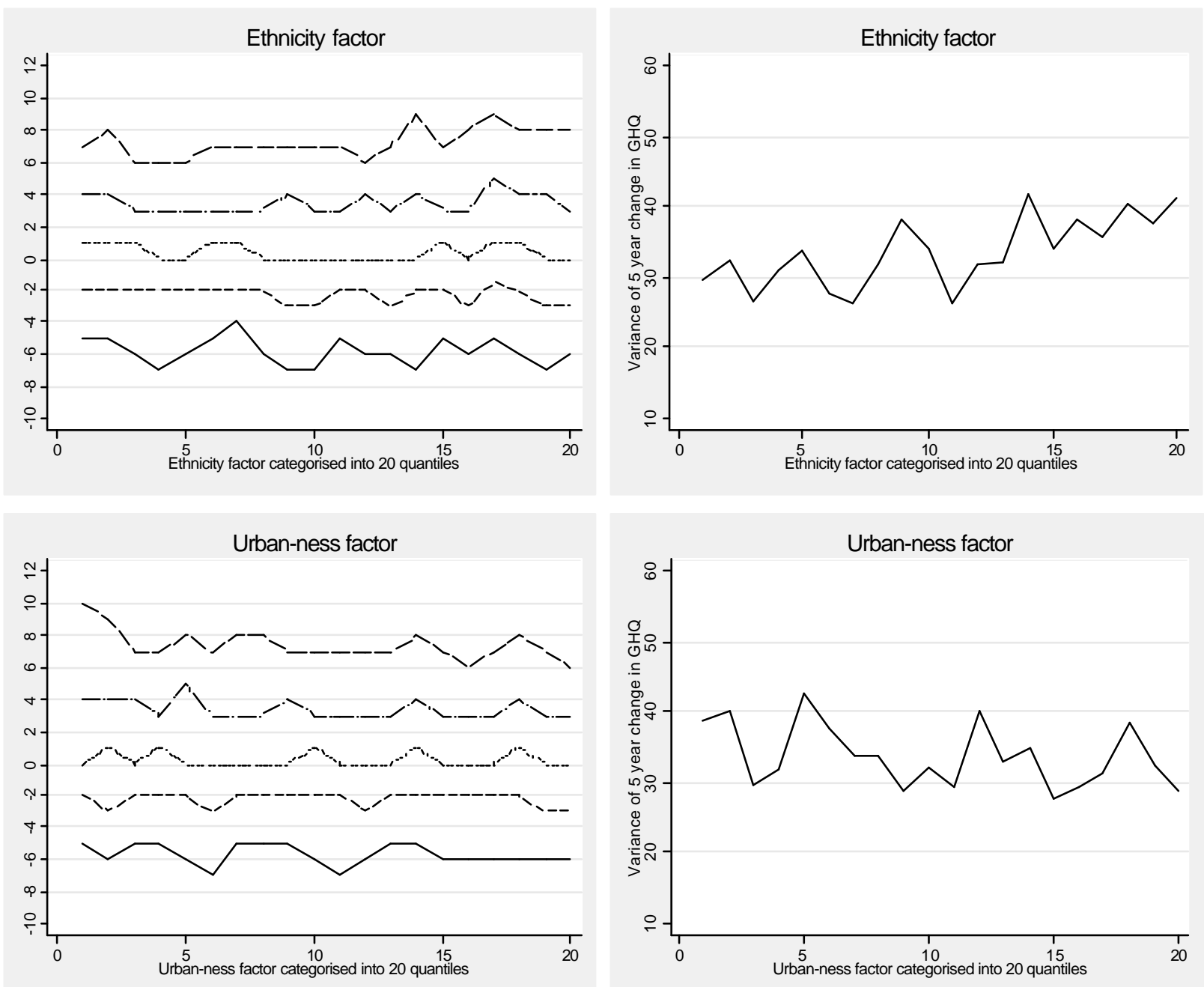
Table 1. Mean and Standard Deviation of Dependent variables

\begin{tabular}{|c|c|c|c|c|}
\hline Variable & Mean & Std. Dev. & Min & Max \\
\hline Mental Health (GHQ) Level & 10.639 & 4.79 & 0 & 36 \\
\hline $\begin{array}{l}\text { Mental Health (GHQ) } 5 \text { year } \\
\text { change }\end{array}$ & 0.643 & 5.80 & -27 & 29 \\
\hline
\end{tabular}

1. Sample size is 8184 for mental health level variable and 7047 for mental health 5 year change variable.

\begin{tabular}{|c|c|c|c|c|c|}
\hline & Disadvantage & Mobility & Age & Ethnicity & $\begin{array}{c}\text { Urban- } \\
\text { ness }\end{array}$ \\
\hline & $\begin{array}{c}\text { Variance }(\chi 2 \\
\text { statistic) }\end{array}$ & $\begin{array}{c}\text { Variance } \\
\quad(\chi 2 \\
\text { statistic }) \\
\end{array}$ & $\begin{array}{c}\text { Variance } \\
\quad(\chi 2 \\
\text { statistic }) \\
\end{array}$ & $\begin{array}{l}\text { Variance } \\
\quad(\chi 2 \\
\text { statistic }) \\
\end{array}$ & $\begin{array}{l}\text { Variance } \\
\quad(\chi 2 \\
\text { statistic }) \\
\end{array}$ \\
\hline \multicolumn{6}{|l|}{ Model 1 (null) } \\
\hline Individual & 19.750 & 19.75 & 19.747 & 19.743 & 19.749 \\
\hline Household & $\begin{array}{c}2.781 \\
(26.73 * *)\end{array}$ & $\begin{array}{c}2.662 \\
(25.45 * *)\end{array}$ & $\begin{array}{c}2.699 \\
(25.80 * *)\end{array}$ & $\begin{array}{c}2.279 \\
(18.79 * *)\end{array}$ & $\begin{array}{c}2.438 \\
(21.02 * *)\end{array}$ \\
\hline Neighbourhood & $\begin{array}{l}0.471 \\
(1.27)\end{array}$ & $\begin{array}{l}0.592 \\
(2.11)\end{array}$ & $\begin{array}{l}0.556 \\
(1.83)\end{array}$ & $\begin{array}{c}0.982 \\
(5.51 *)\end{array}$ & $\begin{array}{l}0.819 \\
(3.76)\end{array}$ \\
\hline Total variance & 23.002 & 23.004 & 23.002 & 23.004 & 23.006 \\
\hline \multicolumn{6}{|l|}{ Model $2^{1}$} \\
\hline Indiv idual & 18.880 & 18.883 & 18.883 & 18.884 & 18.886 \\
\hline Household & $\begin{array}{c}2.576 \\
(26.27 * *)\end{array}$ & $\begin{array}{c}2.311 \\
21.94^{* *)}\end{array}$ & $\begin{array}{c}2.363 \\
(22.61 * *)\end{array}$ & $\begin{array}{c}2.056 \\
(17.42 * *)\end{array}$ & $\begin{array}{c}2.218 \\
\left(19.86^{* *}\right)\end{array}$ \\
\hline Neighbourhood & $\begin{array}{l}0.233 \\
(0.37)\end{array}$ & $\begin{array}{l}0.496 \\
(1.72)\end{array}$ & $\begin{array}{l}0.444 \\
(1.36)\end{array}$ & $\begin{array}{l}0.752 \\
(3.79)\end{array}$ & $\begin{array}{l}0.585 \\
(2.28)\end{array}$ \\
\hline Total variance & 21.689 & 21.690 & 21.690 & 21.6920 & 21.689 \\
\hline $\begin{array}{l}\text { Log } L \text { test of fixed } \\
\text { explanatory } \\
\text { variables }\end{array}$ & $465.25 * *$ & $465.67 * *$ & $465.59 * *$ & $464.49 * *$ & $464.92 * *$ \\
\hline
\end{tabular}

1. Model $1+$ individual and household characteristics 
Table 3. Effect of individual and household on levels of mental health (GHQ score) in 1991

\begin{tabular}{|c|c|c|c|c|c|}
\hline & $\begin{array}{c}\text { Disadvantage } \\
\text { Coeff } \\
(\text { se })\end{array}$ & $\begin{array}{c}\text { Mobility } \\
\text { Coeff } \\
\text { (se) }\end{array}$ & $\begin{array}{c}\text { Age } \\
\text { Coeff } \\
(\text { se })\end{array}$ & $\begin{array}{c}\text { Ethnicity } \\
\text { Coeff } \\
\text { (se) }\end{array}$ & $\begin{array}{c}\text { Urban-ness } \\
\text { Coeff } \\
\text { (se) }\end{array}$ \\
\hline \multirow[t]{2}{*}{ Constant } & $9.27 * *$ & $9.20 * *$ & $9.24 * *$ & $9.21 * *$ & $9.32 * *$ \\
\hline & $(0.49)$ & $(0.49)$ & $(0.49)$ & $(0.49)$ & $(0.49)$ \\
\hline \multirow[t]{2}{*}{ Age } & $0.09 * *$ & $0.089 * *$ & $0.089 * *$ & $0.090 * * *$ & $0.088 * *$ \\
\hline & $(0.02)$ & $(0.02)$ & $(0.02)$ & $(0.02)$ & $(0.02)$ \\
\hline \multirow[t]{2}{*}{ Age squared } & $-0.00078 * *$ & $-0.00080 * *$ & $-0.00080 * *$ & $-0.00080 * *$ & $-0.00079 * *$ \\
\hline & (0.00019) & $(0.00019)$ & $(0.00019)$ & (0.00019) & $(0.00019)$ \\
\hline \multirow[t]{2}{*}{ Female } & $0.92^{* *}$ & $0.92 * *$ & $0.92 * *$ & $0.92 * *$ & $0.92 * *$ \\
\hline & $(0.10)$ & $(0.10)$ & $(0.10)$ & $(0.10)$ & $(0.10)$ \\
\hline \multirow[t]{2}{*}{ Nonwhite } & 0.63 & 0.61 & $0.66^{*}$ & 0.36 & $0.64 *$ \\
\hline & $(0.32)$ & $(0.32)$ & $(0.34)$ & $(0.32)$ & $(0.34)$ \\
\hline \multirow[t]{2}{*}{ Sub o-level } & -0.23 & -0.24 & -0.23 & -0.23 & -0.24 \\
\hline & $(0.20)$ & $(0.20)$ & $(0.20)$ & $(0.20)$ & $(0.20)$ \\
\hline \multirow[t]{2}{*}{ O-level } & -0.32 & -0.32 & -0.32 & -0.31 & -0.33 \\
\hline & $(0.17)$ & $(0.17)$ & $(0.17)$ & $(0.17)$ & $(0.17)$ \\
\hline \multirow[t]{2}{*}{ A-level } & $-0.37 *$ & $-0.38^{*}$ & $-0.37 *$ & $-0.36^{*}$ & $-0.38^{*}$ \\
\hline & $(0.16)$ & $(0.16)$ & $(0.16)$ & $(0.16)$ & $(0.16)$ \\
\hline \multirow[t]{2}{*}{ Higher Education } & $-0.44 *$ & $-0.47 *$ & $-0.46^{*}$ & $-0.44 *$ & $-0.46^{*}$ \\
\hline & $(0.19)$ & $(0.19)$ & $(0.19)$ & $(0.19)$ & $(0.19)$ \\
\hline \multirow[t]{2}{*}{ Household net income } & $-0.025 * *$ & $-0.026 * *$ & $-0.026 * *$ & $-0.026 * *$ & $-0.026 * *$ \\
\hline & $(0.01)$ & $(0.01)$ & $(0.01)$ & $(0.01)$ & $(0.01)$ \\
\hline \multirow[t]{2}{*}{ No. adults in household } & $-0.27 * *$ & -0.26 & $-0.27 * *$ & $-0.27 * *$ & $-0.28 * *$ \\
\hline & $(0.07)$ & $(0.07)$ & $(0.07)$ & $(0.07)$ & $(0.07)$ \\
\hline \multirow[t]{2}{*}{ No. children in household } & 0.05 & 0.05 & 0.05 & 0.05 & 0.05 \\
\hline & $(0.07)$ & $(0.07)$ & $(0.07)$ & $(0.07)$ & $(0.07)$ \\
\hline \multirow[t]{2}{*}{ Tenure: Owned outright } & $-0.53 *$ & $-0.49 *$ & $-0.53 *$ & $-0.53 *$ & $-0.55^{*}$ \\
\hline & $(0.24)$ & $(0.24)$ & $(0.24)$ & $(0.24)$ & $(0.24)$ \\
\hline \multirow[t]{2}{*}{ Tenure: Owned with mortgage } & 0.20 & 0.24 & 0.21 & 0.22 & 0.18 \\
\hline & $(0.21)$ & $(0.21)$ & $(0.21)$ & $(0.21)$ & $(0.22)$ \\
\hline \multirow[t]{2}{*}{ Tenure: Local authority rented } & $0.54 *$ & $0.66 * *$ & $0.65 * *$ & $0.65 * *$ & $0.59 *$ \\
\hline & $(0.25)$ & $(0.25)$ & $(0.25)$ & $(0.25)$ & $(0.26)$ \\
\hline \multirow{2}{*}{$\begin{array}{l}\text { Tenure: Housing association } \\
\text { rented }\end{array}$} & 0.54 & 0.59 & 0.62 & 0.55 & 0.57 \\
\hline & $(0.39)$ & $(0.38)$ & $(0.38)$ & $(0.38)$ & $(0.39)$ \\
\hline \multirow[t]{2}{*}{ Professional } & 0.00 & -0.01 & -0.01 & 0.01 & -0.01 \\
\hline & $(0.30)$ & $(0.30)$ & $(0.30)$ & $(0.30)$ & $(0.30)$ \\
\hline \multirow[t]{2}{*}{ Manager } & -0.35 & -0.36 & -0.36 & -0.35 & -0.35 \\
\hline & $(0.22)$ & $(0.22)$ & $(0.22)$ & $(0.22)$ & $(0.22)$ \\
\hline \multirow[t]{2}{*}{ Skilled manual } & $-0.47 *$ & $-0.45^{*}$ & $-0.45^{*}$ & $-0.46^{*}$ & $-0.45^{*}$ \\
\hline & $(0.22)$ & $(0.22)$ & $(0.22)$ & $(0.22)$ & $(0.22)$ \\
\hline \multirow[t]{2}{*}{ Partly skilled/Unskilled } & -0.28 & -0.27 & -0.26 & -0.27 & -0.25 \\
\hline & $(0.25)$ & $(0.25)$ & $(0.25)$ & $(0.25)$ & $(0.25)$ \\
\hline \multirow[t]{2}{*}{ Unemployed } & $1.72 * *$ & $1.73 * *$ & $1.74 * *$ & $1.72 * *$ & $1.76^{* *}$ \\
\hline & $(0.30)$ & $(0.30)$ & $(0.30)$ & $(0.30)$ & $(0.30)$ \\
\hline \multirow[t]{2}{*}{ Retired } & -0.31 & -0.30 & -0.3 & -0.29 & -0.3 \\
\hline & $(0.28)$ & $(0.28)$ & $(0.28)$ & $(0.28)$ & $(0.28)$ \\
\hline \multirow[t]{2}{*}{ Family care } & $1.61 *$ & $1.58 *$ & $1.63 * *$ & $1.58 *$ & $1.64 * *$ \\
\hline & $(0.63)$ & $(0.63)$ & $(0.63)$ & $(0.63)$ & $(0.63)$ \\
\hline
\end{tabular}




$\begin{array}{lccccc}\text { Student } & 2.33 * * & 2.38 * * & 2.38 * * & 2.37 * * & 2.38 * * \\ & (0.35) & (0.35) & (0.35) & (0.35) & (0.35) \\ \text { Other occupation } & -0.22 & -0.24 & -0.2 & -0.16 & -0.22 \\ & (0.75) & (0.75) & (0.75) & (0.75) & (0.75) \\ \text { Neighbourhood variable } & \text { Included } & \text { Included } & \text { Included } & \text { Included } & \text { Included } \\ & & & & & \\ -2 * \text { Log Likelihood } & 48324.3 & 48325.1 & 48325.9 & 48320.7 & 48324.8 \\ \text { No. observations } & 8184 & 8184 & 8184 & 8184 & 8184 \\ \end{array}$

1. Standard error in parentheses.

2. $* *$ denotes significance at $1 \%$ level, $*$ denotes significance at $5 \%$ level.

3. See Table 4 for estimates of Neighbourhood variables.

4. Omitted categories are noquals/still at school, rented private, skilled non-manual, white, male

Table 4. Effect of neighbourhood characteristics on leve ls of mental health (GHQ score) in 1991

\begin{tabular}{|c|c|c|c|c|c|}
\hline Model & $\begin{array}{c}\text { Disadvantage } \\
\text { Coeff } \\
\text { LR test } \\
\end{array}$ & $\begin{array}{c}\text { Mobility } \\
\text { Coeff } \\
\text { LR test } \\
\end{array}$ & $\begin{array}{c}\text { Age } \\
\text { Coeff } \\
\text { LR test } \\
\end{array}$ & $\begin{array}{c}\text { Ethnicity } \\
\text { Coeff } \\
\text { LR test } \\
\end{array}$ & $\begin{array}{c}\text { Urban-ness } \\
\text { Coeff } \\
\text { LR test } \\
\end{array}$ \\
\hline \multicolumn{6}{|l|}{ Linear } \\
\hline Factor & 0.095 & 0.065 & -0.031 & $0.150 *$ & 0.071 \\
\hline LR test (critical value) & $1.95(3.84)$ & $1.16(3.84)$ & $0.31(3.84)$ & $5.57 *(3.84)$ & $1.46(3.84)$ \\
\hline \multicolumn{6}{|c|}{ Linear + higher order terms } \\
\hline Factor & 0.028 & 0.008 & -0.014 & 0.239 & 0.097 \\
\hline Factor Squared & -0.088 & -0.023 & -0.041 & -0.065 & 0.026 \\
\hline Factor Cubed & 0.045 & 0.016 & -0.005 & 0.007 & 0.003 \\
\hline LR test (critical value) & $3.42(7.82)$ & $2.73(7.82)$ & $1.64(7.82)$ & $6.92(7.82)$ & $1.74(7.82)$ \\
\hline \multicolumn{6}{|l|}{ Linear + linear*female } \\
\hline Factor & -0.08 & 0.061 & -0.058 & 0.051 & 0.069 \\
\hline Factor*female & $0.337 * *$ & 0.007 & 0.052 & 0.197 & 0.005 \\
\hline LR test (critical value) & $12.11 * *(5.99)$ & $1.2(5.99)$ & $0.55(5.99)$ & $9.19 * *(5.99)$ & $1.51(5.99)$ \\
\hline \multicolumn{6}{|l|}{ Linear + linear*nonwhite } \\
\hline Factor & 0.116 & 0.102 & -0.045 & $0.139 *$ & 0.074 \\
\hline Factor*nonwhite & -0.572 & $-0.75 * *$ & 0.642 & 0.05 & -0.098 \\
\hline LR test (critical value) & $5.31(5.99)$ & $9.66 * *(5.99)$ & $3.12(5.99)$ & $5.75(5.99)$ & $1.53(5.99)$ \\
\hline \multicolumn{6}{|l|}{$\begin{array}{l}\text { Linear + linear*higher } \\
\text { education }\end{array}$} \\
\hline Factor & 0.128 & 0.05 & -0.061 & 0.198 & 0.063 \\
\hline Factor*higher education & -0.277 & 0.062 & 0.198 & $-0.359 *$ & 0.051 \\
\hline LR test (critical value) & $4.18(5.99)$ & $1.39(5.99)$ & $1.99(5.99)$ & $10.61 * *(5.99)$ & $1.56(5.99)$ \\
\hline \multicolumn{6}{|l|}{ Linear + all interactions } \\
\hline Factor & -0.031 & 0.091 & -0.098 & 0.08 & 0.065 \\
\hline Factor*female & $0.342 * *$ & -0.009 & 0.048 & 0.214 & 0.001 \\
\hline Factor*nonwhite & -0.533 & $-0.753 * *$ & 0.616 & 0.63 & -0.102 \\
\hline Factor*higher education & -0.282 & 0.069 & 0.183 & $-0.378^{*}$ & 0.052 \\
\hline LR test (critical value) & $17.66 * *(9.49)$ & $9.94 *(9.49)$ & $4.82(9.49)$ & $14.84 * *(9.49)$ & $1.68(9.49)$ \\
\hline
\end{tabular}

1 .** denotes significance at $1 \%$ level, $*$ denotes significance at $5 \%$ level. 
Table 5. Effect on prediction of Mental Health (GHQ) Level of gender, race, higher education.

\begin{tabular}{lccccc}
\hline Factor & Percentile of Factor & $\begin{array}{c}\text { GHQ } \\
\text { prediction at } \\
\text { base }\end{array}$ & $\begin{array}{c}\text { Female relative } \\
\text { to male }\end{array}$ & $\begin{array}{c}\text { Nonwhite } \\
\text { relative to } \\
\text { white }\end{array}$ & $\begin{array}{c}\text { Higher } \\
\text { education } \\
\text { relative to no } \\
\text { qualifications }\end{array}$ \\
\hline Disadvantage & $10^{\text {th }}$ & 10.41 & 0.54 & 1.22 & -0.13 \\
Mobility & $90^{\text {th }}($ Poor $)$ & 10.34 & 1.35 & -0.04 & -0.80 \\
Age & $10^{\text {th }}$ & 10.23 & 0.93 & 1.32 & -0.53 \\
Ethnicity & $90^{\text {th }}($ Mobile $)$ & 10.44 & 0.91 & -0.35 & -0.38 \\
Ruralness & $10^{\text {th }}$ & 10.45 & 0.86 & -0.08 & -0.68 \\
S.D. of GHQ & $90^{\text {th }}($ Young) & 10.22 & 0.97 & 1.37 & -0.25 \\
\hline
\end{tabular}

1. Predictions of GHQ1 based on model with linear Factor term and all interactions (with gender, race and higher education).

2. Counterfactual in each case is male, white, skilled non-manual, renter, no qualifications. All other explanatory variables are set at their means.

3. Shading indicates that the interaction term is significant, see Table 4.

Table 6. Variance and proportion of total variance of mental health 5 year change (GHQ score) at individual, household and neighbourhood level.

\begin{tabular}{|c|c|c|c|c|c|}
\hline & Disadvantage & Mobility & Age & Ethnicity & Urban-ness \\
\hline & $\begin{array}{c}\text { Variance }(\chi 2 \\
\text { statistic) }\end{array}$ & $\begin{array}{c}\text { Variance } \\
(\chi 2 \\
\text { statistic })\end{array}$ & $\begin{array}{c}\text { Variance } \\
\quad\left(\chi^{2}\right. \\
\text { statistic })\end{array}$ & $\begin{array}{c}\text { Variance } \\
(\chi 2 \\
\text { statistic })\end{array}$ & $\begin{array}{c}\text { Variance } \\
(\chi 2 \\
\text { statistic })\end{array}$ \\
\hline \multicolumn{6}{|l|}{ Model 1 (null) } \\
\hline Individual & 29.061 & 28.47 & 29.066 & 29.057 & 28.472 \\
\hline Household & $\begin{array}{c}3.869 \\
\left(20.35^{* *}\right)\end{array}$ & $\begin{array}{c}4.664 \\
(26.06 * *)\end{array}$ & $\begin{array}{c}4.262 \\
(24.19 * *)\end{array}$ & $\begin{array}{c}3.801 \\
\left(19.68^{* *}\right)\end{array}$ & $\begin{array}{c}4.414 \\
(22.78 * *)\end{array}$ \\
\hline Neighbourhood & $\begin{array}{l}0.785 \\
(2.34)\end{array}$ & $\begin{array}{l}0.606 \\
(0.80)\end{array}$ & $\begin{array}{c}0.39 \\
(0.99)\end{array}$ & $\begin{array}{l}0.864 \\
(3.00)\end{array}$ & $\begin{array}{l}0.858 \\
(1.49)\end{array}$ \\
\hline Total variance & 33.715 & 33.740 & 33.718 & 33.722 & 33.744 \\
\hline \multicolumn{6}{|l|}{ Model $2^{1}$} \\
\hline Individual & 28.890 & 28.305 & 28.889 & 28.872 & 28.297 \\
\hline Household & $\begin{array}{c}3.574 \\
\left(17.90^{* *}\right)\end{array}$ & $\begin{array}{c}4.385 \\
\left(23.55^{* *}\right)\end{array}$ & $\begin{array}{c}4.051 \\
\left(21.85^{* *}\right)\end{array}$ & $\begin{array}{c}3.554 \\
\left(17.29^{* *}\right)\end{array}$ & $\begin{array}{c}4.127 \\
(20.34 * *)\end{array}$ \\
\hline Neighbourhood & $\begin{array}{l}0.954 \\
(3.14)\end{array}$ & $\begin{array}{l}0.740 \\
(1.19)\end{array}$ & $\begin{array}{l}0.478 \\
(1.42)\end{array}$ & $\begin{array}{c}0.993 \\
\left(3.87^{*}\right)\end{array}$ & $\begin{array}{l}1.006 \\
(2.06)\end{array}$ \\
\hline Total variance & 33.418 & 33.430 & 33.418 & 33.419 & 33.430 \\
\hline $\begin{array}{l}\text { Log L test of fixed } \\
\text { explanatory } \\
\text { variables }\end{array}$ & $65.89 * *$ & $63.21 * *$ & $65.25^{* *}$ & $65.78 * *$ & $63.32 * *$ \\
\hline
\end{tabular}


Table 7. Effect of individual and household on 5 year changes in mental health (GHQ score)

\begin{tabular}{|c|c|c|c|c|c|}
\hline & $\begin{array}{c}\text { Disadvantage } \\
\text { Coeff } \\
(\text { se }) \\
\end{array}$ & $\begin{array}{c}\text { Mobility } \\
\text { Coeff } \\
(\text { se })\end{array}$ & $\begin{array}{l}\text { Age } \\
\text { Coeff } \\
(\mathrm{se}) \\
\end{array}$ & $\begin{array}{c}\text { Ethnicity } \\
\text { Coeff } \\
\text { (se) } \\
\end{array}$ & $\begin{array}{c}\text { Urban-ness } \\
\text { Coeff } \\
\text { (se) }\end{array}$ \\
\hline \multirow[t]{2}{*}{ Constant } & 0.95 & 0.80 & 1.00 & 1.02 & 0.91 \\
\hline & $(0.66)$ & $(0.66)$ & $(0.66)$ & $(0.66)$ & $(0.66)$ \\
\hline \multirow[t]{2}{*}{ Age } & -0.04 & -0.03 & -0.04 & -0.04 & -0.03 \\
\hline & $(0.02)$ & $(0.02)$ & $(0.02)$ & $(0.02)$ & $(0.02)$ \\
\hline \multirow[t]{2}{*}{ Age squared } & 0.00032 & 0.00031 & 0.00031 & 0.00031 & 0.00030 \\
\hline & (0.00028) & $(0.00028)$ & $(0.00028)$ & $(0.00028)$ & $(0.00028)$ \\
\hline \multirow[t]{2}{*}{ Female } & $0.42 * *$ & $0.42 * *$ & $0.42 * *$ & $0.42 * *$ & $0.42 * *$ \\
\hline & $(0.13)$ & $(0.13)$ & $(0.13)$ & $(0.13)$ & $(0.13)$ \\
\hline \multirow[t]{2}{*}{ Nonwhite } & -0.32 & -0.32 & -0.33 & -0.34 & -0.33 \\
\hline & $(0.27)$ & $(0.27)$ & $(0.27)$ & $(0.27)$ & $(0.27)$ \\
\hline \multirow[t]{2}{*}{ Sub o-level } & -0.21 & -0.21 & -0.23 & -0.24 & -0.23 \\
\hline & $(0.23)$ & $(0.23)$ & $(0.23)$ & $(0.23)$ & $(0.23)$ \\
\hline \multirow[t]{2}{*}{ O-level } & -0.18 & -0.20 & -0.21 & -0.22 & -0.21 \\
\hline & $(0.22)$ & $(0.22)$ & $(0.22)$ & $(0.22)$ & $(0.22)$ \\
\hline \multirow[t]{2}{*}{ A-level } & -0.28 & -0.34 & -0.31 & -0.32 & -0.30 \\
\hline & $(0.26)$ & $(0.26)$ & $(0.26)$ & $(0.26)$ & $(0.26)$ \\
\hline \multirow[t]{2}{*}{ Higher Education } & 0.60 & 0.55 & 0.63 & 0.84 & 0.64 \\
\hline & $(0.43)$ & $(0.43)$ & $(0.43)$ & $(0.47)$ & $(0.43)$ \\
\hline \multirow[t]{2}{*}{ Household net income } & 0.00 & 0.00 & 0.00 & 0.00 & 0.00 \\
\hline & $(0.01)$ & $(0.01)$ & $(0.01)$ & $(0.01)$ & $(0.01)$ \\
\hline \multirow[t]{2}{*}{ No. adults in household } & 0.06 & 0.08 & 0.05 & 0.05 & 0.06 \\
\hline & $(0.09)$ & $(0.09)$ & $(0.09)$ & $(0.09)$ & $(0.09)$ \\
\hline \multirow[t]{2}{*}{ No. children in household } & 0.13 & 0.13 & 0.11 & 0.11 & 0.11 \\
\hline & $(0.09)$ & $(0.09)$ & $(0.09)$ & $(0.09)$ & $(0.09)$ \\
\hline \multirow[t]{2}{*}{ Tenure: Owned outright } & 0.47 & 0.57 & 0.46 & 0.46 & 0.49 \\
\hline & $(0.32)$ & $(0.32)$ & $(0.32)$ & $(0.32)$ & $(0.32)$ \\
\hline \multirow[t]{2}{*}{ Tenure: Owned with mortgage } & 0.25 & 0.35 & 0.25 & 0.25 & 0.31 \\
\hline & $(0.28)$ & $(0.28)$ & $(0.28)$ & $(0.28)$ & $(0.28)$ \\
\hline \multirow[t]{2}{*}{ Tenure: Local authority rented } & -0.03 & 0.20 & 0.13 & 0.13 & 0.24 \\
\hline & $(0.34)$ & $(0.33)$ & $(0.33)$ & $(0.33)$ & $(0.33)$ \\
\hline \multirow[t]{2}{*}{$\begin{array}{l}\text { Tenure: Housing association } \\
\text { rented }\end{array}$} & 0.43 & 0.51 & 0.52 & 0.57 & 0.63 \\
\hline & $(0.51)$ & $(0.51)$ & $(0.51)$ & $(0.51)$ & $(0.51)$ \\
\hline \multirow[t]{2}{*}{ Professional } & 0.01 & 0.00 & -0.01 & -0.02 & 0.00 \\
\hline & $(0.39)$ & $(0.39)$ & $(0.39)$ & $(0.39)$ & $(0.39)$ \\
\hline \multirow[t]{2}{*}{ Manager } & 0.34 & 0.31 & 0.32 & 0.31 & 0.30 \\
\hline & $(0.28)$ & $(0.28)$ & $(0.28)$ & $(0.28)$ & $(0.28)$ \\
\hline \multirow[t]{2}{*}{ Skilled manual } & 0.23 & 0.26 & 0.25 & 0.25 & 0.23 \\
\hline & $(0.28)$ & $(0.28)$ & $(0.28)$ & $(0.28)$ & $(0.28)$ \\
\hline \multirow[t]{2}{*}{ Partly skilled/Unskilled } & -0.37 & -0.34 & -0.35 & -0.34 & -0.39 \\
\hline & $(0.32)$ & $(0.32)$ & $(0.32)$ & $(0.32)$ & $(0.32)$ \\
\hline \multirow[t]{2}{*}{ Unemployed } & $-1.54 * *$ & $-1.53 * *$ & $-1.52 * *$ & $-1.50 * *$ & $-1.55^{* *}$ \\
\hline & $(0.39)$ & $(0.39)$ & $(0.39)$ & $(0.39)$ & $(0.39)$ \\
\hline \multirow[t]{2}{*}{ Retired } & 0.15 & 0.17 & 0.15 & 0.15 & 0.14 \\
\hline & $(0.37)$ & $(0.37)$ & $(0.37)$ & $(0.37)$ & $(0.37)$ \\
\hline \multirow[t]{2}{*}{ Family care } & -0.84 & -0.86 & -0.84 & -0.82 & -0.86 \\
\hline & $(0.51)$ & $(0.51)$ & $(0.51)$ & $(0.51)$ & $(0.51)$ \\
\hline
\end{tabular}




$\begin{array}{lccccc}\text { Student } & -0.57 & -0.49 & -0.51 & -0.50 & -0.53 \\ & (0.49) & (0.49) & (0.49) & (0.49) & (0.49) \\ \text { Other occupation } & -1.44^{*} & -1.44^{*} & -1.44^{*} & -1.45^{*} & -1.46^{*} \\ & (0.72) & (0.72) & (0.72) & (0.72) & (0.72) \\ \text { Neighbourhood variable } & \text { Included } & \text { Included } & \text { Included } & \text { Included } & \text { Included } \\ & & & & & \\ -2 * \text { Log Likelihood } & 44651.54 & 44650.53 & 44655.09 & 44654.04 & 44651.25 \\ \text { No. observations } & 7047 & 7047 & 7047 & 7047 & 7047 \\ & & & & & \end{array}$

1. Standard error in parentheses.

2. $* *$ denotes significance at $1 \%$ level, * denotes significance at $5 \%$ level.

3. See Table 8 for estimates of Neighbourhood variables.

4. Omitted categories are noquals/still at school, rented private, skilled non-manual, white, male

Table 8. Effect of neighbourhood characteristics on 5 year changes in mental health (GHQ score)

\begin{tabular}{cccccc}
\hline \multirow{3}{*}{ Model } & Disadvantage & Mobility & Age & Ethnicity & Urban-ness \\
& Coeff & Coeff & Coeff & Coeff & Coeff \\
& LR test & LR test & LR test & LR test & LR test \\
\hline
\end{tabular}

\section{Linear}

Factor

0.175

Ler test

LR test

LR test

LR test (critical value)

$3.7(3.84) \quad 4.71 *(3.84) \quad 0.15(3.84) \quad 1.2(3.84) \quad 3.99 *(3.84)$

Linear + higher order terms

Factor

Factor Squared

$\begin{array}{lcccc}0.18 & 0.24^{*} & 0.05 & 0.12 & -0.19 \\ 0.02 & 0.16 & 0.09 & -0.03 & 0.05 \\ -0.01 & -0.05^{*} & -0.01 & 0.00 & 0.01 \\ .7(7.82) & 9.89 *(7.82) & 3.8(7.82) & 5.66(7.82) & 5.09(7.82)\end{array}$

LR test (critical value)

(7.82)

\section{Linear + linear*female}

Factor

$\begin{array}{ccccc}0.110 & 0.040 & 0.117 & -0.101 & -0.014 \\ 0.120 & 0.257 & -0.152 & 0.018 & -0.262 \\ 46(5.99) & 8.23 *(5.99) & 1.36(5.99) & 1.2(5.99) & 7.45 *(5.99)\end{array}$

Factor*female

4.46 (5.99)

$8.23 *(5.99)$

$1.36(5.99)$

$1.2(5.99)$

$7.45^{*}(5.99)$

\section{Linear + linear*nonwhite}

$\begin{array}{lccccc}\text { Factor } & 0.177 & 0.139 & 0.033 & 0.006 & -0.168^{*} \\ \text { Factor*nonwhite } & -0.089 & 0.709^{*} & 0.053 & -0.376^{*} & 0.330 \\ \text { LR test (critical value) } & 3.79(5.99) & 8.78^{*}(5.99) & 0.13(5.99) & 5.29(5.99) & 4.49(5.99)\end{array}$

Linear + linear*higher education

$\begin{array}{lccccc}\text { Factor } & 0.102 & 0.181 * & -0.008 & -0.136 & -0.198^{*} \\ \text { Factor*higher education } & 0.542^{*} & -0.032 & 0.249 & 0.312 & 0.257 \\ \text { LR test (critical value) } & 9.07 *(5.99) & 4.73(5.99) & 1.83(5.99) & 3.57(5.99) & 5.53(5.99) \\ & & & & & \\ \text { Linear + all interactions } & & & & & -0.058 \\ \text { Factor } & 0.048 & 0.013 & 0.075 & -0.049 & -0.277^{*} \\ \text { Factor*female } & 0.109 & 0.260 & -0.153 & 0.02 & 0.274 \\ \text { Factor*nonwhite } & -0.176 & 0.719 * & 0.014 & -0.369 * & 0.285 \\ \text { Factor*higher education } & 0.545^{*} & -0.038 & 0.250 & 0.303 & 0.76 *(9.49) \\ \text { LR test (critical value) } & 9.87^{*}(9.49) & 12.33^{*}(9.49) & 3.06(9.49) & 7.54(9.49) & 9.76(4)\end{array}$

1. ** denotes significance at $1 \%$ level, $*$ denotes significance at $5 \%$ level. 
Table 9. Effect on prediction of Mental Health (GHQ) 5 year change of gender, race, higher education.

\begin{tabular}{|c|c|c|c|c|c|}
\hline Factor & Percentile of Factor & $\begin{array}{c}\text { GHQ } 5 \text { year } \\
\text { change } \\
\text { prediction at } \\
\text { base }\end{array}$ & $\begin{array}{c}\text { Female relative } \\
\text { to male }\end{array}$ & $\begin{array}{c}\text { Nonwhite } \\
\text { relative to } \\
\text { white }\end{array}$ & $\begin{array}{c}\text { Higher } \\
\text { education } \\
\text { relative to no } \\
\text { qualifications }\end{array}$ \\
\hline \multirow[t]{2}{*}{ Disadvantage } & $10^{\text {th }}$ & 0.33 & 0.30 & 0.80 & -0.88 \\
\hline & $90^{\text {th }}$ (Poor) & 0.45 & 0.56 & 0.38 & 0.41 \\
\hline \multirow[t]{2}{*}{ Mobility } & $10^{\text {th }}$ & 0.27 & 0.18 & -0.13 & -0.30 \\
\hline & $90^{\text {th }}$ (Mobile) & 0.30 & 0.76 & 1.47 & -0.39 \\
\hline \multirow[t]{2}{*}{ Age } & $10^{\text {th }}$ & 0.27 & 0.61 & 0.62 & -0.61 \\
\hline & $90^{\text {th }}$ (Young) & 0.44 & 0.25 & 0.65 & -0.02 \\
\hline \multirow[t]{2}{*}{ Ethnicity } & $10^{\text {th }}$ & 0.38 & 0.41 & 1.03 & -0.48 \\
\hline & $90^{\text {th }}$ (Ethnically mixed) & 0.33 & 0.43 & 0.63 & -0.15 \\
\hline \multirow[t]{2}{*}{ Ruralness } & $10^{\text {th }}$ & 0.37 & 0.70 & 0.37 & -0.59 \\
\hline & $90^{\text {th }}$ (Urban) & 0.27 & 0.18 & 0.88 & -0.05 \\
\hline S.D. of GHQ & & & 5.80 & 5.80 & 5.80 \\
\hline
\end{tabular}

1. Predictions of GHQ1 based on model with linear Factor term and all interactions (with gender, race and higher education).

2. Counterfactual in each case is male, white, skilled non-manual, renter, no qualifications. All other explanatory variables are set at their means.

3. Shading indicates that the interaction term is significant, see Table 8. 